\title{
Mfledia \\ HUBUNGAN KANDUNGAN TOTAL POLIFENOL DAN FLAVONOID DENGAN POTENSI ANTIMIKROBA LIMBAH KANGKUNG DAN BAYAM TERHADAP PERTUMBUHAN BAKTERI PENYEBAB INFEKSI NOSOKOMIAL
}

\author{
Correlation Between Total Polyphenol And Flavonoid Contents With Antimicrobial Potential Of Kale \\ And Spinach Waste Against Bacterial Growth Causing Nosocomial Infection
}

Alfrida Monica Salasa, St. Ratnah*

Poltekkes Kemenkes Makassar

*Koresponden Email: ratnah.mansjur@poltekkes-mks.ac.id

\begin{abstract}
Spinach and kale are vegetables that are widely consumed by the public. However, parts of the plant that are not consumed are discarded and end up as household organic waste. Therefore, this research aims to determine the total polyphenol and flavonoid levels, as well as the potential of household organic waste as an antimicrobial cause of nosocomial infections. The household organic waste used in this research were untreated and waste parts of kale and spinach, extracted by the extortion method and then dried using a freeze dryer. Furthermore, the total polyphenol content was determined using the Folin-Ciocalteau method, the total flavonoids with $\mathrm{AlCl}_{3}$ reagent, and the antimicrobial potential using the agar diffusion method. The results showed that the total polyphenol content in kale and spinach waste were 4.67 and $3.91 \mathrm{mg}$ GAE / gram extract respectively. Water spinach and spinach waste do not contain flavonoids, meanwhile, kale and spinach waste have antimicrobial potential against Pseudomonas aeruginous and Staphylococcus aureus. The statistical results showed that there was a relationship between the total polyphenol content and the antimicrobial potential of Kale and spinach waste extracts, the higher the concentration of the extract the greater the inhibition against Pseudomonas aeruginous and Staphylococcus aureus.
\end{abstract}

Keywords : Total polyphenols, total flavonoids, antimicrobial potential, organic household waste, nosocomial infections.

\begin{abstract}
ABSTRAK
Bayam dan kangkung merupakan sayuran yang sering dikonsumsi masyarakat namun bagian tanaman yang tidak dikonsumsi dibuang dan berakhir sebagai limbah rumah tangga organik. Tujuan penelitian ini adalah untuk menentukan kandungan total polifenol dan total flavonoid, menentukan potensi limbah rumah tangga organik sebagai antimikroba penyebab infeksi nosocomial serta menentukan hubungan kandungan total polifenol dan kandungan total plavonoid terhadap potensi antimikroba limbah rumah tangga terhadap pertumbuhan bakteri penyebab nosocomial. Limbah rumah tangga organik yang digunakan adalah bagian kangkung dan bayam yang tidak diolah dan dikonsumsi, diekstraksi dengan metode perasan kemudian dikeringkan dengan menggunakan freeze dryer. Selanjutnya dilakukan uji kandungan total polifenol dengan metode Folin-Ciocalteau dan total flavonoid dengan pereaksi $\mathrm{AlCl}_{3}$, penentuan potensi antimikroba dengan metode difusi agar. Hasil yang diperoleh kandungan total polifenol pada limbah kangkung sebesar 4,67 mg GAE/gram ekstrak sedangkan untuk Ekstrak limbah Bayam sebesar 3,91 mg GAE/gram ekstrak. Limbah Kangkung dan Bayam tidak mengandung senyawa flavonoid. Limbah Kangkung dan Bayam memiliki potensi antimikroba terhadap Pseudomonas aeruginosae dan Staphylococcus aureus. Hasil uji statistik menunjukkan Terdapat hubungan antara kandungan total polifenol dengan potensi antimikroba ekstrak limbah Kangkung dan Bayam dimana semakin tinggi konsentrasi ekstrak semakin besar daya hambatnya terhadap Pseudomonas aeruginosae dan Staphylococcus aureus
\end{abstract}

Kata Kunci : Total polifenol, total flavonoid, potensi antimikroba, limbah rumah tangga organik, infeksi nosokomial. 


\section{PENDAHULUAN}

Masyarakat urban atau masyarakat perkotaan adalah kelompok manusia yang tinggal di sebuah wilayah besar, padat, profesinya beragam dan heterogen. Seiring meningkatnya jumlah penduduk, maka akan berdampak pada meningkatnya jumlah sampah termasuk sampah atau limbah rumah tangga. Pengelolaan limbah rumah tangga yang tidak baik menyebabkan terjadinya penumpukan sampah yang akan membusuk dan mengeluarkan aroma yang tidak sedap sehingga mencemari lingkungan dan menyebabkan gangguan kesehatan. Limbah rumah tangga terdiri dari limbah organik dan limbah anorganik. Limbah organik berupa sisa-sisa makanan, serta bagian sayuran dan buah yang tidak dikonsumsi.

Indonesia merupakan Negara dengan keanekaragaman tanaman, baik tanaman yang digunakan sebagai obat tradisional maupun tanaman yang dikonsumsi sebagai sayur dan buah-buahan untuk memenuhi kebutuhan gizi. Semua tanaman mengandung senyawa kimia yang disebut senyawa fitokemikal seperti tannin, flavonoid, steroid dan senyawa lainnya. Senyawa fitokemikal tersebut memiliki efek terapeutik baik terhadap penyakit infeksi maupun penyakit degenerative.

Sayuran dan buah-buahan yang dikonsumsi untuk memenuhi kebutuhan gizi juga mengandung senyawa fitokemikal seperti yang terkandung dalam tanaman yang digunakan di masyarakat sebagai obat tradisional. Sayuran dan buah yang sering dikonsumsi di masyarakat adalah kangkung, sawi, bayam, wortel, dan pepaya. Tetapi tidak semua bagian diolah dan dikonsumsi seperti batang tua, akar dan kulit buah. Bagian yang tidak digunakan dibuang dan menjadi limbah rumah tangga, padahal bagian tersebut masih mengandung senyawa fitokemikal.

Menurut Yuliana (2013), kangkung air (Ipomoea aquatic Forssk.) mengandung senyawa polifenol, flavonoid dan kunon. Sayuran lain yang sering dikonsumsi masyarakat adalah bayam. Bayam mengandung senyawa flavonoid, tannin dan steroid atau triterpenoid (Limbong, E.,P., 2017). Menurut Novita dkk (2016) kandungan total fenol yang terhitung sebagai GAE dalam daun kangkung sebesar $0,94 \mathrm{mg} / \mathrm{gram}$ dan bayam sayur sebesar $1,41 \mathrm{mg} / \mathrm{gram}$.

Infeksi nosokomial yang sekarang disebut dengan Healthcare Associated Infections (HAIs) adalah infeksi yang diperoleh pada saat berada di tempat pelayanan kesehatan. Mikroorganisme penyebab infeksi nosokomial diantaranya adalah Staphylococcus aureus, Escherichia coli, Pseudomonas aeruginosa, Kleibsiella pneumoniae, Candida albicans dll (Tortora, et al, 1995).

Pada penelitian ini menggunakan bahan uji limbah kangkung dan bayam yang merupakan bagian sayuran yang paling sering dikonsumsi oleh masyarakat dan sampel Staphylococcus aureus dan Pseudomonas aeruginosae yang merupakan penyebab infeksi nosokomial.

Rumusan masalah dari penelitian ini adalah apakah limbah kangkung dan bayam berpotensi sebagai antibakteri penyebab infeksi nosokomial?

Tujuan dari penelitian ini adalah untuk menentukan kandungan total polifenol dan total flavonoid, potensi antibakteri serta hubungan kandungan total polifenol dan kandungan total flavonoid terhadap potensi antimikroba limbah kangkung dan bayam terhadap pertumbuhan bakteri penyebab nosocomial

\section{METODE}

\section{Desain, tempat dan waktu}

Penelitian ini merupakan penelitian laboratorium dan telah dilaksanakan pada bulan Januari - September 2020 di Laboratorium Kimia, Laboratorium Teknologi Farmasi dan Laboratorium Mikrobiologi Poltekkes Kemenkes Makassar.

\section{Alat dan Bahan}

Alat yang digunakan yaitu juicer, autoklaf, cawan petri, gelas kimia, incubator, neraca analitik, oven, rak tabung, tabung reaksi.

Bahan yang digunakan yaitu limbah rumah tangga organik (kangkung dan bayam), Nutrien broth, Nutrien agar, Pepton Water, spoit $1 \mathrm{cc}$, spoit $3 \mathrm{cc}$, spoit $5 \mathrm{cc}$, spoit $10 \mathrm{cc}$, aqua pro injeksi, Staphylococcus aureus, Pseudomonas aeruginosa dan aquadest.

\section{Sampel Penelitian}

Sampel pada penelitian ini adalah Staphylococcus aureus dan Pseudomonas aeruginosa.

\section{Prosedur Penelitian \\ Pengambilan Bahan Uji}

Bahan uji berupa limbah rumah tangga organik yang merupakan bagian dari sayuran dan buah yang tidak diolah dan dikonsumsi yang terdiri dari batang dan akar kangkung serta batang dan akar bayam. 


\section{Pengolahan Bahan Uji}

Bahan uji dipisahkan dari kotoran, dicuci bersih dengan air kemudian ditiriskan. Setelah itu dirajang untuk mempermudah proses ekstraksi

\section{Ekstraksi}

Masing-masing bahan uji ditimbang kemudian diekstraksi dengan metode perasan menggunakan juicer. Selanjutnya Ekstrak limbah yang diperoleh dikeringkan dengan menggunakan freeze dryer.

\section{Pengujian Kandungan Total Polifenol Uji Kualitatif Polifenol}

Ekstrak dilarutkan dengan $2 \mathrm{ml}$ etanol 96\% ditambahkan dengan peraksi Ferri klorida $10 \%$. Terbentuknya warna biru tua, biru kehitaman atau hitam kehijauan menunjukkan ekstrak mengandung senyawa polifenol (Hanani E., 2016)

\section{Uji Kuantitatif Total Polifenol}

\section{Pembuatan Kurva Baku Asam Gallat}

Dibuat pengenceran larutan standar dengan konsentrasi 20, 40, 60, 80 dan 100 ppm. Dari masing larutan tersebut diambil $0,3 \mathrm{~mL}$ dimasukkan ke dalam vial lalu ditambahkan 1,5 mL pereaksi Folin-Ciocalteau (1:10) diamkan selama 3 menit lalu tambahkan 1,2 mL larutan $\mathrm{Na}_{2} \mathrm{CO}_{3} 7,5 \%$ kemudian dibiarkan selama 30 menit lalu absorban larutan diukur pada panjang gelombang $756 \mathrm{~nm}$

Penetapan Kandungan Total Polifenol dari masing-masing ekstrak limbah rumah tangga organik (Chun et al, 2005)

Ekstrak sebanyak $100 \mathrm{mg}$ dan dilarutkan dengan etanol $96 \%$ sampai volume tepat 10,0 $\mathrm{mL}$. Diambil 0,3 $\mathrm{mL}$ dari pengenceran ekstrak, kemudian dimasukkan ke dalam vial, ditambahkan 1,5 $\mathrm{ml}$ reagen Folin-Ciocalteau (1:10) didiamkan selama 3 menit setelah itu ditambahkan 1,2 mL Natrium Karbonat 7,5\% kemudian didiamkan selama 30 menit. Setelah itu absorbansi larutan diukur pada panjang gelombang $756 \mathrm{~nm}$. Konsentrasi dihitung dari persamaan regresi larutan asam gallat standar. Dilakukan replikasi sebanyak 3 kali.

\section{Pengujian Kadar Total Flavonoid Uji Kualitatif Flavonoid}

Ekstrak ditambah etanol, tambahkan sedikit logam $\mathrm{Mg}$ serta beberapa tetes $\mathrm{HCl}$ pekat. Terbentuknya warna merah magenta menunjukkan ekstrak mengandung flavonoid.

\section{Analisis Kuantitatif Flavonoid}

\section{Pembuatan Kurva Baku kuercetin}

Dibuat seri pengenceran 10, 20, 30, 40, dan 50 ppm sebanyak $10 \mathrm{~mL}$. Sebanyak $0,5 \mathrm{ml}$ masing-masing konsentrasi dimasukkan ke dalam labu ukur $10 \mathrm{ml}$, kemudian ditambahkan $100 \mu \mathrm{L} \mathrm{AlCl}_{3} 10 \%$ dan $100 \mu \mathrm{L}$ larutan Natrium asetat $1 \mathrm{M}$ lalu dicukupkan volumenya hingga tanda dengan air suling. Larutan didiamkan selama 30 menit lalu absorbannya diukur pada panjang gelombang 400-800 $\mathrm{nm}$.

Penetapan Kandungan Total Flavonoid dari masing-masing Ekstrak Limbah Rumah Tangga Organik

Ekstrak sebanyak 0,25 g dan dilarutkan dengan $50 \mathrm{ml}$ etanol $70 \% \quad(5000 \mu \mathrm{g} / \mathrm{ml})$. Sebanyak 0,5 ml masing-masing konsentrasi dimasukkan ke dalam labu tentukur $10 \mathrm{ml}$, kemudian ditambahkan $100 \mu \mathrm{L} \mathrm{AlCl}_{3} 10 \%$ dan $100 \mu \mathrm{L}$ larutan Natrium asetat $1 \mathrm{M}$ lalu dicukupkan volumenya sampai tanda dengan air suling. Larutan dibiarkan selama 30 menit lalu absorbannya diukur pada panjang gelombang 400-800 nm.

Penentuan Potensi Aktivitas Antimikroba Limbah Rumah Tangga Terhadap Bakteri Penyebab infeksi Nosokomial

Penyiapan Ekstrak

Bahan uji dibuat dengan mengencerkan maing-masing ekstrak dari limbah rumah tangga organik menggunakan air steril. Konsentrasi bahan uji yang digunakan adalah $25 \%, 50 \%$, $75 \%$ dan $100 \%$ b/v

Pengujian Potensi Limbah Rumah Tangga Organik Sebagai Antimikroba Penyebab Infeksi Nosokomial

Disiapkan media MHA steril, kemudian dimasukkan ke dalam cawan petri steril lalu dibiarkan media menjadi padat. $\mathrm{Ke}$ dalam masing-masing larutan ekstrak yang telah disuspensikan dengan $\mathrm{Na} \mathrm{CMC}$, larutan Clindamycin 50 ppm dan Ciplofloxacin 50 ppm (kontrol positif) dan larutan Na CMC (kontrol negatif) yang telah disiapkan dimasukkan paper disc kemudian dibiarkan beberapa saat lalu ditiriskan. Diulas bakteri pada permukaan media yang telah padat kemudian dibiarkan selama 15 menit. Setelah itu, paper disc yang telah ditiriskan diletakkan pada permukaan media yang telah diulas dengan bakteri. Setelah itu diinkubasi pada suhu $37^{\circ} \mathrm{C}$ selama 1 x 24 jam. Diamati zona bening yang terbentuk disekitar paper disc, kemudian diukur diameter zona hambat tersebut menggunakan jangka sorong. Zona bening yang terbentuk disekitar paper disc 
HASIL

Tahap-tahap pengujian dalam penelitian adalah ekstraksi, penetuan kandungan total polifenol, kandungan total flavonoid serta potensi aktivitas antimikroba limbah rumah tangga organik khususnya kangkung dan bayam terhadap bakteri penyebab infeksi nosokomial yaitu Pseudomonas aureginosae dan Staphylococcus aureus. Hasil pengujian dapat dilihat di bawah ini:

1. Penentuan Total Polifenol Sebagai Asam Galat dalam limbah Kangkung dan Bayam

Tabel 1. Uji Kualitatif Senyawa Polifenol Dalam Limbah Kangkung dan bayam

\begin{tabular}{ccccc}
\hline No & Ekstrak & Pereaksi & Pengamatan & Kesimpulan \\
\hline 1 & Limbah Kangkung & $\mathrm{FeCl}_{3}$ & Larutan Biru & + polifenol \\
2. & Limbah bayam & $\mathrm{FeCl}_{3}$ & Larutan Biru & + polifenol \\
\hline
\end{tabular}

Tabel 2 Hasil Pengujian Total Polifenol Ekstrak Limbah Kangkung dan Bayam

\begin{tabular}{clc}
\hline No. & \multicolumn{1}{c}{ Ekstrak } & mg GAE/gram ekstrak \\
\hline 1. & Limbah Kangkung & 4,67 \\
2. & Limbah Bayam & 3,91 \\
\hline
\end{tabular}

2. Penentuan Total Flavonoid Sebagai Kuersetin dalam limbah Kangkung dan Bayam

Tabel 3 Uji Kualitatif Senyawa Flavonoid Dalam Limbah Kangkung dan bayam

\begin{tabular}{ccccc}
\hline No & Ekstrak & Pereaksi & Pengamatan & Kesimpulan \\
\hline 1 & Limbah Kangkung & HCl pekat + logam Mg & hijau & - flavonoid \\
2. & Limbah bayam & HCl pekat + logam Mg & hijau & - flavonoid \\
\hline
\end{tabular}

3. Pengujian potensi aktivitas antimikroba limbah Kangkung dan Bayam terhadap bakteri Pseudomonas aeruginosae dan Staphylococcus aureus

Tabel 4 Potensi aktivitas antimikroba limbah kangkung dan bayam terhadap bakteri Pseudomonas aeruginosae

\begin{tabular}{cccccccc}
\hline \multirow{2}{*}{ No } & \multirow{2}{*}{ Ekstrak } & \multirow{2}{*}{ Replikasi } & \multicolumn{5}{c}{ Diameter zona hambat (mm) } \\
\cline { 3 - 7 } & & $\mathbf{2 5 \%}$ & $\mathbf{5 0 \%}$ & $\mathbf{7 5 \%}$ & $\mathbf{1 0 0 \%}$ & Ciprofloksasin \\
\hline \multirow{3}{*}{1} & I & 8 & 10 & 12 & 13 & 23 \\
& Limbah & II & 8 & 9 & 10 & 11 & 23 \\
& Kangkung & III & 8 & 9 & 11 & 13 & 20 \\
\cline { 3 - 7 } & & Rata-rata & $\mathbf{8}$ & $\mathbf{9 , 3 3}$ & $\mathbf{1 1}$ & $\mathbf{1 2 . 3 3}$ & $\mathbf{2 2}$ \\
\hline \multirow{3}{*}{2} & I & 8 & 9 & 11 & 12 & 23 \\
& \multirow{2}{*}{ Limbah } & II & 8 & 10 & 11 & 12 & 23 \\
& Bayam & III & 8 & 9 & 11 & 12 & 23 \\
\cline { 3 - 7 } & & Rata-rata & $\mathbf{8}$ & $\mathbf{9 . 3 3}$ & $\mathbf{1 1}$ & $\mathbf{1 2}$ & $\mathbf{2 3}$ \\
\hline
\end{tabular}

Data : Primer 2020

Tabel 5 Potensi aktivitas antimikroba limbah kangkung dan bayam terhadap bakteri Staphylococcus aureus

\begin{tabular}{|c|c|c|c|c|c|c|c|}
\hline \multirow{2}{*}{ No } & \multirow{2}{*}{ Ekstrak } & \multirow{2}{*}{ Replikasi } & \multicolumn{5}{|c|}{ Diameter zona hambat (mm) } \\
\hline & & & $25 \%$ & $50 \%$ & $75 \%$ & $100 \%$ & Klindamisin \\
\hline \multirow{4}{*}{1} & \multirow{4}{*}{$\begin{array}{l}\text { Limbah } \\
\text { Kangkung }\end{array}$} & I & 10 & 12 & 13 & 14 & 21 \\
\hline & & II & 9 & 12 & 13 & 14 & 22 \\
\hline & & III & 9 & 11 & 12 & 13 & 22 \\
\hline & & Rata-rata & 9,33 & 11,66 & 12,66 & 13,66 & 21,66 \\
\hline \multirow{4}{*}{2} & \multirow{4}{*}{$\begin{array}{l}\text { Limbah } \\
\text { Bayam }\end{array}$} & I & 8 & 10 & 11 & 13 & 21 \\
\hline & & II & 9 & 10 & 11 & 12 & 21 \\
\hline & & III & 8 & 11 & 12 & 13 & 21 \\
\hline & & Rata-rata & 8.33 & 10.33 & 11,66 & 12,66 & 21 \\
\hline
\end{tabular}

Data : Primer 2020 


\section{PEMBAHASAN}

Penelitian ini bertujuan untuk menentukan kandungan total polifenol dan kandungan total flavonoid serta potensi aktivitas antimikroba limbah rumah tangga organik terhadap bakteri Pseudomonas aeruginosae dan Staphylococcus aureus. Penelitian ini bermanfaat sebagai data ilmiah dimana data ini dapat digunakan sebagai acuan dalam membuat berbagai sediaan yang dapat digunakan sebagai antiseptik atau desinfektan dalam mencegah penyakit yang disebabkan bakteri penyebab infeksi nosokomial.

Limbah rumah tangga organik adalah limbah rumah tangga yang berupa sayuran dan buah yang tidak dikonsumsi dan dibuang. Dalam penelitian ini limbah rumah tangga yang diuji adalah limbah kangkung dan bayam yang berupa bagian daun tua, batang serta akar yang tidak dikonsumsi. Pemilihan sayur kangkung dan bayam karena merupakan sayuran yang paling digemari oleh masyarakat dan paling sering dikonsumsi serta sayuran tersebut memiliki kandungan fitokemikal seperti senyawa polifenol dan flavonoid.

Tahapan pengerjaan yang dilakukan adalah ekstraksi, penentuan kandungan total polifenol dan kandungan total flavonoid serta potensi aktivitas antimikroba terhadap bakteri Pseudomonas aeruginosae dan Staphylococcus aureus. Ekstraksi limbah kangkung dan bayam menggunakan metode perasan karena merupakan metode yang sederhana serta mudah diaplikasikan kepada masyarakat. Ekstraksi dilakukan untuk menarik semua senyawa fitokemikal yang terdapat dalam limbah tersebut

Pengujian total polifenol dilakukan untuk mengetahui kandungan total senyawa total polifenol yang terdapat dalam ekstrak limbah kangkung dan bayam. Pengujian ini diawali dengan uji kualitatif dengan menggunakan pereaksi Feri klorida untuk mengidentifikasi keberadaan senyawa polifenol dalam ekstrak limbah kangkung dan bayam. Hasil pengujian diperoleh terbentuknya warna biru yang menunjukkan bahwa kedua ekstrak limbah tersebut mengandung senyawa polifenol (tabel 4.1). Kemudian pengujian dilanjutkan dengan menentukan kandungan total senyawa polifenol dengan menggunakan pereaksi FolinCiocalteau. Asam galat digunakan sebagai standar karena merupakan fenol alami dan stabil. Hasil pengujian diperoleh kandungan total polifenol yang setara dengan asam galat (mg GAE/gram ekstrak) untuk ekstrak limbah kangkung sebesar 4,67 mg/gram ekstrak dan untuk ekstrak limbah bayam sebesar 3,91 $\mathrm{mg} /$ gram ekstrak (tabel 4.2).
Pengujian total flavonoid dilakukan untuk mengetahui kandungan total senyawa flavonoid yang terdapat dalam ekstrak limbah kangkung dan bayam. Pengujian ini diawali dengan uji kualitatif dengan menggunakan pereaksi logam $\mathrm{Mg}$ dan $\mathrm{HCl}$ pekat. Apabila terbentuk warna merah, jingga atau kuning menunjukkan mengandung senya flavonoid. Hasil pengujian diperoleh terbentuknya warna hijau yang menunjukkan bahwa ekstrak limbah kangkung dan bayam tidak mengandung senyawa flavonoid (tabel 4.3). Untuk pengujian kandungan total flavonoid tidak dilanjutkan karena pada uji kualitatif menunjukkan kedua ekstrak tersebut tidak mengandung senyawa flavonoid.

Pengujian potensi antimikroba kedua ekstrak tersebut dilakukan dengan metode difusi agar. Potensi antimikroba dilakukan terhadap bakteri Pseudomonas aeruginosae dan Staphylococcus aureus, karena merupakan bakteri penyebab infeksi nosokomial. Konsentrasi ekstrak yang digunakan adalah, $25 \%, 50 \%, 75 \%$ dan $100 \%$ b/v. Kontrol positif yang digunakan adalah Ciprofloksacin dan Clindamycin. Potensi antimikroba dapat dilihat dengan adanya zona bening disekitar paper disc yang diletakkan pada permukaan media yang telah diulas dengan bakteri Pseudomonas aeruginosae dan Staphylococcus aureus. Zona bening tersebut merupakan zona hambat ekstrak terhadap pertumbuhan bakteri. Hasil pengujian potensi antimikroba ekstrak limbah kangkung terhadap Pseudomonas aeruginosae diperoleh diameter zona hambat rata untuk konsentrasi $25 \%$ sebesar $8 \mathrm{~mm}, 50 \%$ sebesar $9,33 \mathrm{~mm} ; 75 \%$ sebesar $11 \mathrm{~mm}$; dan 100\% sebesar 12,33 mm. Sedangkan untuk ekstrak limbah bayam diperoleh diameter zona hambat untuk konsentrasi $25 \%$ sebesar $8 \mathrm{~mm} ; 50 \%$ sebesar $9,33 \mathrm{~mm} ; 75 \%$ sebesar $11 \mathrm{~mm}$; dan $100 \%$ sebesar $12 \mathrm{~mm}$. Diameter zona hambat untuk Ciprofloksacin adalah sebesar $23 \mathrm{~mm}$. Hasil pengujian potensi antimikroba ekstrak limbah kangkung terhadap Staphylococcus aureus diperoleh diameter zona hambat rata untuk konsentrasi $25 \%$ sebesar $9,33 \mathrm{~mm}, 50 \%$ sebesar $11,66 \mathrm{~mm} ; 75 \%$ sebesar $12,66 \mathrm{~mm}$; dan $100 \%$ sebesar 13,66 mm. Sedangkan untuk ekstrak limbah Bayam diperoleh diameter zona hambat untuk konsentrasi $25 \%$ sebesar $8,33 \mathrm{~mm} ; 50 \%$ sebesar 10,33 mm; 75\% sebesar 11,66 mm; dan $100 \%$ sebesar 12,66 mm. Diameter zona hambat untuk Clindamycin adalah sebesar 21,33 mm.

Terbentuknya zona bening disekitar paper disc yang menunjukkan daya hambat ekstrak limbah kangkung dan Bayam terhadap bakteri Pseudomonas aeruginoasae dan 
Staphylococcus aureus. Hal ini disebabkan karena ekstrak Kangkung dan Bayam mengandung senyawa polifenol dimana senyawa ini dapat merusak dan menembus dinding sel bakteri, kemudian mengendapkan protein sel mikroba sehingga merupakan racun bagi protoplasma (Ngajow dkk, 2013). Hal ini menunjukkan bahwa ekstrak tersebut memiliki potensi aktivitas antimikroba terhadap kedua bakteri tersebut.

Hasil pengujian statistik menggunakan uji Mann Withney menunjukkan bahwa konsentrasi ekstrak limbah Kangkung yang memberikan aktivitas antimikroba yang terbesar terhadap Pseudomonas aeruginosae dan Staphylococcus aureus adalah $75 \%$ b/v. Konsentrasi ekstrak limbah Bayam yang memberikan aktivitas antimikroba yang terbesar terhadap Pseudomonas aeruginosae adalah $100 \% \mathrm{~b} / \mathrm{v}$ dan terhadap Staphylococcus aureus adalah $75 \% \mathrm{~b} / \mathrm{v}$.

Uji korelasi Spearman antara kandungan total polifenol terhadap potensi antimikroba ekstrak limbah Kangkung dan Bayam menunjukkan bahwa ada hubungan signifikan antara peningkatan konsentrasi ekstrak dan potensi antimikroba dimana semakin tinggi konsentrasi ekstrak semakin besar daya hambat ekstrak tersebut terhadap bakteri Pseudomonas aeruginosae dan Staphylococcus aureus $(\mathrm{p}=0,01)$

\section{KESIMPULAN}

Berdasarkan hasil penelitian dan analisis data dapat disimpulkan bahwa :

1. Kandungan total polifenol sebagai asam galat untuk ekstrak Limbah Kangkung sebesar 4,67 mg GAE/gram ekstrak sedangkan untuk Ekstrak limbah Bayam sebesar 3,91 mg GAE/gram ekstrak

2. Ekstrak limbah Kangkung dan Bayam tidak mengandung senyawa flavonoid.

3. Ekstrak limbah Kangkung dan Bayam memiliki potensi antimikroba terhadap Pseudomonas aeruginosae dan Staphylococcus aureus $(\mathrm{p}<0,05)$

4. Semakin tinggsi konsentrasi ekstrak semakin besar daya hambatnya terhadap
Pseudomonas aeruginosae dan Staphylococcus aureus

\section{DAFTAR PUSTAK}

Chun, O.K., Kim, D.O., and Lee, C.Y., 2003, Superoxide Radical Scavenging Activity of The Major Polyphenols in Fresh Plums, J. Agric. Food Chem, 51, 80678072.

Hanani, E., 2016, Analisis Fitokimia, Penerbit EGC Medical Publisher, Jakarta

Lay, B.W. 2002 Analisis Mikroba Di Laboratorium. Jakarta: PT. Raja Grafindo Persada

Limbong, E., P., 2017, Uji Aktivitas Antibakteri Ekstrak Etranol Daun Bayam Merah (Athernanthera strigosa Hask) Terhadap Bakteri Staphylococcus aureus dan Escherichia coli. Repisatory Skripsi Universitas Sumatra Utara

Ngajow M., Abidjulu J., Kamu V.S. Pengaruh Antibakteri Ekstrak KUlit Batang Matoa (Pometia pinnata) Terhadap Bakteri Staphylococcus aureus secara In Vitro. Jurnal MIPa,2. 128 - 132

Novita M., M.Iksan Sulaiman, Saufa Yura. 2016. Pengaruh Jenis Pelarut Terhadap Aktivitas Antioksidan dan Kandungan Fenol Beberapa Jenis Bayam dan Sayuran Lain. Jurnal Ilmiah Mahasiswa Pertanian Unsyiah Vol. 1 No. 1, Nov 2016

Tortora Gerard J, et.al, 2001, Microbiology : An Introduction, Edisi 7, Pearson Education. USA, http://www.fk.uwks.ac.id/elib/Arsip/Dep artemen/Mikrobiologi/inp.pdf. Diakses tanggal 28 Agustus 2019.

Yuliana, A., Albert, 2013, Aktivitas Kangkung Air (Ipomoea aquatic Forssk.) Terhadap Jamur Pityrosporum ovale Hasil Isolasi Secara In Vitro, Jurnal Kesehatan Bakti Tunas Husada.

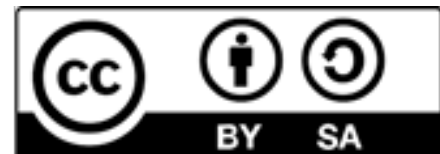

